\title{
Studies on the Hydrogen Evolution Reaction on Fe-Co- Ni/Stainless Steel Electrode
}

\author{
Isana SYL ${ }^{1}$, Wega Trisunaryanti ${ }^{2}$, Agus Kuncaka ${ }^{3}$, Triyono ${ }^{4}$ \\ ${ }^{I}$ Chemical Education Departement, Mathematics and Science Faculty of Yogyakarta State University, \\ Indonesia; Doctor Candidate from Chemistry Departement, Mathematics and Science Faculty of Gadjah Mada \\ University, Indonesia \\ ${ }^{2,3,4}$ Chemistry Departement, Mathematics and Science Faculty of Gadjah Mada University, Indonesia
}

\begin{abstract}
The Fe, Co and Ni metals were coated onto stainless steel substrat under various compositions in a linear voltammetric to prepare $\mathrm{Fe}$ (1-5)-Co-Ni/s electrocatalyst electrodes with stainless steel as working electrode, $\mathrm{Ag} / \mathrm{AgCl}$ as a reference electrode and platinum as an auxiliary electrode. The integer number (1 to 5) after the Fe metal shown the percentage of Fe content (wt.\%) on the Fe1-5-Co-Ni/s electrodes 57.09, 61.96, 68.07, 71.81 and $74.71 \mathrm{wt}$.\%. The composition of stainless steel substrat before coating is determined by SEMEDAX. The Characters of Fe1-5-Co-Ni/s as electrocatalyst electrodes were determined by linear and cyclic voltammetric methods and SEM-EDAX method. The voltammetric methods studied electrochemical behavior, and SEM-EDAX method studied electrode surface morfology and determine semiquantitative elemental composition. The Fe1-5-Co-Ni/s electrodes had been applied for water electrolysis in base solution by adding 1 - 5 gram of $\mathrm{NaHCO}_{3}$ in one liter water.

The study of SEM-EDAX conducted that the higher of Fe content the lower of activity. Before coating the amount of $\mathrm{Ni}$ was not detected. The present of Ni after coating was detected by SEM-EDAX. The voltammetric data showed that coating of ternary metal of $\mathrm{Fe}$, Co and Ni onto stainless steel substrat have been able to enhanced the rate of the reaction of hydrogen evolution. The Fel-Co-Ni/s electrocatalyst electrode (the amount of $\mathrm{Fe}$, Co and $\mathrm{Ni}$ was 57.09, 0.22 and $0.74 \mathrm{wt} . \%$ respectivelly) is the most active catalyst for water electrolysis in base solution of 5 gram of $\mathrm{NaHCO}_{3}$ in one liter water.
\end{abstract}

Keyword: stainless steel, coating, Fel-5-Co-Ni/s electrocatalyst electrodes

\section{Introduction}

Hydrogen gas is an alternative fuel which is friendly and safety toward surroundings. However, the produce of hydrogen with high efficiency and safety storage still has many problems that need to be solved. Water electrolysis, that is one of process make hydrogen gas as fuel, has low efficiency and other problems. Therefore, it is necessary to create electrolysis conditions with serious efforts which are possible to gain high efficiency of hydrogen production.

Water electrolysis process depends on many factors, one of them are electrodes. In general, properties of electrodes in water electrolysis have enduring of corrosion so they are not being rapidly deactivated. To protect the electrode from corrosion, Nobel metal is usually used as electrod such as platinum. Platinum electrode is very expensive, thus it is necessary to try other metals, like alliage or composite as electrode in water electrolysis process. Properties of stainless steels are enduring from corrosion, impurity and oxidation; easier treatment and inexpensive so it is possible to use as electrode in water electrolysis process. Using other metals besides noble metals as electrodes in water electrolysis is less effective in general, both in term of the efficiency side of product and enduring from corrosion especially if using it as anode. Other metals besides noble metals are possible to use it as cathode in water electrolysis process however they have lower efficiency. Using other metals besides platinum as cathodes in water electrolysis process, it needs special handling to increase catalytic effectivity and activity.

Coating binary composite of nickel base, such as Ni-Mo, Ni-Zn, Ni-Co, Ni-W, Ni-Fe and Ni-Cr has been fabricated and studied by Raj dan Vasu [1]. It was tried for hydrogen electrodes; out of these electrodes, $\mathrm{Ni}-\mathrm{Mo}$ was found to be best and most stable electrode with overpotential of $0.18 \mathrm{~V}$ in $6 \mathrm{M} \mathrm{KOH}$ solutions. Coating composite of nickel base onto stainless steel substrat or cuprum has been studied for application as cathodes in industrial electrochemical production for hydrogen. Composite coated Raney nickel and thermally coated Ni/Mo coating electrodes were shown to exhibit higher electrocatalytic activities for hydrogen evolution reaction in alkaline solution but they were deactivated after two weeks due to power passivations [2-3].

Coating ternary composite of $\mathrm{Ni}$ base, such as Ni-Mo-Fe, Ni-Mo-Cu, Ni-Mo-Zn, Ni-Mo-W, Ni-Mo-Co and $\mathrm{Ni}-\mathrm{Mo}-\mathrm{Cr}$ were studied for hydrogen evolution and the authors reported that the best and most stable cathode was Ni-Mo-Fe [4]. Coating cathode by electrodeposition with $\mathrm{Ni}-\mathrm{S}, \mathrm{Ni}-\mathrm{Mo}, \mathrm{Ni}-\mathrm{Ti}$, Ni-Mo-Si, and $\mathrm{Ni}-$ Fe-Mo-Zn has been fabricated and studied for hydrogen production by Han and Liu, He, et al, Sanches, et al, 
Panek, et al, Kubisztal and Budniok, Kubisztal, et al, Crnkovic, et al [5-11]. Coating composite film of Ni-MoFe onto stainless steel substrat has been fabricated and studied by Jayalakshmi, et al [12]. Ternary Ni-Mo-Fe film coated on stainless steel substrate was found to be catalytic to hydrogen evolution in dilute alkali solutions. The overpotentials for both hydrogen and oxygen evolutions were minimum in $0.1 \mathrm{M} \mathrm{NaOH}$ solution. The potential window between the oxygen and hydrogen evolutions was the lowest in $0.1 \mathrm{M} \mathrm{NaOH}$ solution which is highly desired for water electrolysis. Coating nickel alliage with the left transition metals (W, Mo, and Fe) has been fabricated and studied by Navarro-Flores, et al [13]. It had shown to increase the intrinsic electrocatalytic activity in the hydrogen evolution reaction compared to pure nickel. Coating composite film of $\mathrm{Ni}, \mathrm{Mo}, \mathrm{Fe}, \mathrm{Co}$ and $\mathrm{S}$ onto nickel, graphite, stainless steel, steel and $\mathrm{Pt} / \mathrm{Si}$ substrats has been fabricated and studied the effect of substrates on the electrochemical behavior of Ni-Mo-Fe-Co-S composite film in alkali solutions [14]. Ni-Mo$\mathrm{Fe}-\mathrm{Co}-\mathrm{S}$ composite film coated on graphite, stainless steel, steel and nickel were catalytic to hydrogen evolution in alkali solution but on $\mathrm{Pt} / \mathrm{Si}$ were not.

Research of $\mathrm{Fe}-\mathrm{Co}-\mathrm{Ni} / \mathrm{s}$ electrocatalyst electrodes is a new research because others had not been doing it. The research will be applied to produce Hydrogen gas from water electrolysis in base solution. $\mathrm{Fe}, \mathrm{Co}$ and $\mathrm{Ni}$ metals are transition metals with incomplete $\mathrm{d}$ orbital, so it is possible having catalytic property. $\mathrm{Fe}$, Co and $\mathrm{Ni}$ metals, which have atomic number 26,27 , and 28 , are classified as the $8^{\text {th }}$ (VIIIB) group on periodic table. The similarity of atomic size and potential electrodes, $-0.41 \mathrm{~V}\left(\mathrm{Fe}^{2+} / \mathrm{Fe}\right),-0.28 \mathrm{~V}\left(\mathrm{Co}^{2+} / \mathrm{Co}\right)$, and $-0.23 \mathrm{~V}\left(\mathrm{Ni}^{2+} / \mathrm{Ni}\right)$, make it possible to patch onto stainless steel substrat equally. Thus the three metals electrodeposition on are stainless steel substrates expected to succeed simultaneously with a favorable position and could be applied as an electrocatalyst electrode in hydrogen evolution. Moreover, $\mathrm{Fe}, \mathrm{Co}$ and $\mathrm{Ni}$ metals are very abundant in nature so easily obtained and have low prices. Thus the $\mathrm{Fe}-\mathrm{Co}-\mathrm{Ni} / \mathrm{s}$ could be used as an electrocatalyst electrode because it is safer and cheaper, and has a relatively high efficiency.

Based on consideration above, in this research, I tried to using stainless steel substrat which is coated of $\mathrm{Fe}-\mathrm{Co}-\mathrm{Ni}$ metals with linear voltammetric methods, afterwards would be used as electrocatalyst electrodes ( $\mathrm{Fe}-$ $\mathrm{Co}-\mathrm{Ni} / \mathrm{s}$ ) to produce hydrogen gas from water electrolysis in base solution.

\section{Experimental}

\subsection{Chemicals}

Stainless steel ferritic grades S-430 type, thickness $=1.2 \mathrm{~mm}$, width $=3 \mathrm{~mm}$ and length $=110 \mathrm{~mm}$, nitric acid, acetone, $\mathrm{NaHCO}_{3}$ p.a, $\mathrm{FeSO}_{4} .7 \mathrm{H}_{2} \mathrm{O}$ p.a, $\mathrm{Co}\left(\mathrm{NO}_{3}\right)_{2} .6 \mathrm{H}_{2} \mathrm{O}$ p.a, $\mathrm{NiSO}_{4} \cdot 6 \mathrm{H}_{2} \mathrm{O}$ p.a, $\mathrm{H}_{3} \mathrm{BO}_{3}$, saccharin, $\mathrm{NaCl}, \mathrm{NH}_{4} \mathrm{Cl}$ and aquadest.

\subsection{Equipments}

Glassware for preparation and activity test, electrolysis tube, eDAQ EChem for voltammetric analysis, SEMEDAX (scanning electron microscopy-energy dispersive X-ray) for studying morfology of electrode surfaces and determining composition of semiquantitative elemental, and GSA (gas sorption analysis) for determining specific surface area, total pore volume and pore radius by BJH (Barrett, Joyner \& Halenda) method.

\subsection{Electrodeposition of Fe1-5-Co-Ni}

\section{onto stainless steel}

Fe1-5-Co-Ni/s electrocatalyst electrodes had fabricated by linear voltammetric with stainless steel as working electrode, platinum as auxiliary electrode and $\mathrm{Ag} / \mathrm{AgCl}$ as reference electrode. Application of Fe1-5$\mathrm{Co}-\mathrm{Ni} / \mathrm{s}$ electrocatalyst electrodes had been used to produce hydrogen gas pass through water electrolysis in base solutions (adding $1-5 \mathrm{~g} \mathrm{NaHCO}_{3}$ in one liter water), with three electrodes, those are $\mathrm{Fe} 1-5-\mathrm{Co}-\mathrm{Ni} / \mathrm{s}$ as working electrodes, platinum as auxiliary electrode and $\mathrm{Ag} / \mathrm{AgCl}$ as reference electrode.

\subsection{Characterisation of Fe1-5-Co- Ni/s Electrocatalyst Electrodes \\ III. Result And Discussion}

Based on linear voltammetric, electrodeposition potential of Fe1-5-Co-Ni/s electrodes was $-0.858 \mathrm{~V}$, $0.788 \mathrm{~V},-0.844 \mathrm{~V},-0.874 \mathrm{~V}$, and $0.284 \mathrm{~V}$ respectively against $\mathrm{Ag} / \mathrm{AgCl}$. Electrodeposition potential of Fe1-4Co-Ni/s electrodes did not show significant difference, approximately $-0.8 \mathrm{~V}$ (negative value) but for Fe5-Co$\mathrm{Ni} / \mathrm{s}$ electrode shown significant difference, approximately $0.3 \mathrm{~V}$ (positive value). This indicated that electrodeposition of Fe5-Co-Ni/s was more spontaneously than Fe1-4-Co-Ni/s.

Based on cyclic voltamogram of Fe1-5-Co-Ni/s electrodes, current density of Fe3-Co-Ni/s electrode was the widest. Voltammograms of a sample has specific peculiarities that can distinguish qualitatively and quantitatively. Based on linear and cyclic voltammetric data, it had shown that Fe1-5-Co-Ni/s electrodes had specific curves and SEM images, so they can be distinguished form the stainless steel. These conditions indicated that electrodeposition process of the ternary metal on the stainless steel substrat occured. The 
phenomenon was also supported by cyclic voltammogram of Fe1-5-Co-Ni/s electrodes on water electrolysis that increased its cathodic and anodic current peaks.

SEM-EDAX image of Fe1-5-Co-Ni/s electrodes had shown in Fig. 1. The amount of Fe, Co and $\mathrm{Ni}$ in stainless steel substrat before coating was 80.11 wt. \% (Fe) and 0.05 wt. \% (Co), and undetected $\mathrm{Ni}$. Electrodeposition of $\mathrm{Fe} 1-5-\mathrm{Co}-\mathrm{Ni}$ on stainless steel substrat shown that the amount of $\mathrm{Fe}$ was increased, that was appropriate with composition of solutions, but the amount of Co and $\mathrm{Ni}$ was deposited variously. The amount of Fe in stainless steel substrat was detected more than electrodeposition product. It shown that electrodeposition not only Fe patch on substrat but also Co and Ni patch. Various amounts of Co and Ni shown that activities of $\mathrm{Co}$ dan $\mathrm{Ni}$ were different, despite of the compositions of $\mathrm{Co}$ and $\mathrm{Ni}$ in solutions was equal. $\mathrm{Ni}$ precipitates easier than $\mathrm{Co}$. It is appropriate with standard potential electrode of $\mathrm{Ni}$ which is more than $\mathrm{Co}$.
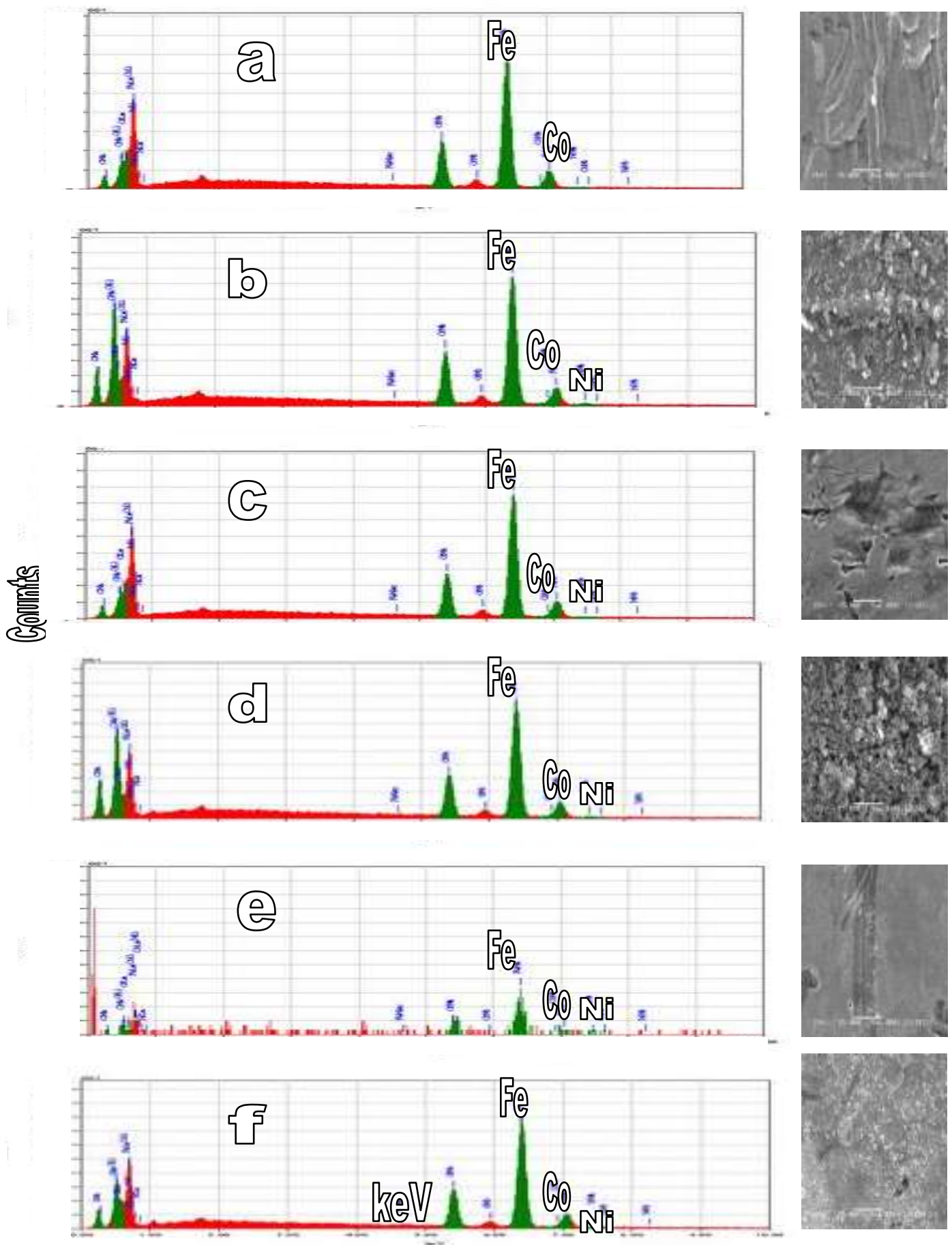

Fig. 1 SEM-EDAX image of (a) stainless steel substrat and (b-f) Fe1-5-Co$\mathrm{Ni} / \mathrm{s}$ Electrodes 
Based on GSA data can be determined of specific surface area, total pore volume and pore radius of stainless steel and Fe1-5-Co-Ni/s electrodes by BJH method, as shown in Table 1. The surface area, and cathodic and anodic current peaks of $\mathrm{Fe} 1-5-\mathrm{Co}-\mathrm{Ni} / \mathrm{s}$ are higher than stainless steel, in general. This result conduct the assumption that the hydrogen evolution process more favorable when the coated stainless steel used, shown in Table 2.

\begin{tabular}{|c|c|c|c|}
\hline Electrode & $\begin{array}{c}\text { Specific surface area } \\
\left(\mathbf{m}^{\mathbf{2}} / \mathbf{g}\right)\end{array}$ & $\begin{array}{c}\text { Total pore volume } \\
(\mathbf{c c} / \mathbf{g})\end{array}$ & $\begin{array}{c}\text { Pore radius } \\
(\AA)\end{array}$ \\
\hline Stainless steel & 6,628 & 0,0106 & 15,318 \\
\hline $\mathrm{Fe} 1-\mathrm{Co}-\mathrm{Ni} / \mathrm{s}$ & 6.970 & 0.0112 & 35.1935 \\
\hline $\mathrm{Fe} 2-\mathrm{Co}-\mathrm{Ni} / \mathrm{s}$ & 6.703 & 0.0117 & 39.7427 \\
\hline $\mathrm{Fe} 3-\mathrm{Co}-\mathrm{Ni} / \mathrm{s}$ & 10.759 & 0.017 & 31.2414 \\
\hline $\mathrm{Fe} 4-\mathrm{Co}-\mathrm{Ni} / \mathrm{s}$ & 6.691 & 0.0108 & 34.3068 \\
\hline $\mathrm{Fe} 5-\mathrm{Co}-\mathrm{Ni} / \mathrm{s}$ & 9.150 & 0.0145 & 30.6516 \\
\hline
\end{tabular}

Table 1. Data of specific surface area, total pore volume and pore radius of Fe1-5-Co-Ni/selectrodes

\begin{tabular}{|c|c|c|c|c|c|}
\hline No & Electrode & $\begin{array}{c}\mathbf{i}_{\mathbf{c}} \\
(\mathbf{m A})\end{array}$ & $\begin{array}{c}\mathbf{i}_{\mathbf{a}} \\
(\mathbf{m A})\end{array}$ & $\begin{array}{c}\text { Ratio of cathodic peak } \\
\text { electrodes to stainless steel } \\
\text { electrode }\end{array}$ & $\begin{array}{c}\text { Ratio of anodic peak } \\
\text { electrodes to stainless } \\
\text { steel electrode }\end{array}$ \\
\hline 1 & Stainless steel & 0.052 & 0.414 & 1 & 1 \\
\hline 2 & $\mathrm{Fe} 1-\mathrm{Co}-\mathrm{Ni} / \mathrm{s}$ & 1.684 & 4.548 & 32.20 & 10.99 \\
\hline 3 & $\mathrm{Fe} 2-\mathrm{Co}-\mathrm{Ni} / \mathrm{s}$ & 1.026 & 3.250 & 19.62 & 7.85 \\
\hline 4 & $\mathrm{Fe} 3-\mathrm{Co}-\mathrm{Ni} / \mathrm{s}$ & 0.727 & 2.919 & 13.90 & 7.05 \\
\hline 5 & $\mathrm{Fe}-\mathrm{Co}-\mathrm{Ni} / \mathrm{s}$ & 1.103 & 2.169 & 21.09 & 5.24 \\
\hline 6 & $\mathrm{Fe} 5-\mathrm{Co}-\mathrm{Ni} / \mathrm{s}$ & 1.099 & 2.794 & 21.01 & 6.75 \\
\hline
\end{tabular}

Table 2. Cathodic and anodic peak of Fe1-5-Co-Ni/s electrodes of water electrolysis by adding 5 gram of $\mathrm{NaHCO}_{3}$ in one liter water

\subsection{Electrochemical Study of $\mathrm{Fe}-\mathrm{Co}-\mathrm{Ni} / \mathrm{s}$}

It had shown that The Fe1-5-Co-Ni/s electrodes can improve of stainless steel properties in water electrolysis reaction in base solutions (Fig. 2). The Fe1-Co-Ni/s electrodes of water electrolysis by adding 5 gram of $\mathrm{NaHCO}_{3}$ in one liter water were the most effective condition to produce hydrogen and oxygen gas. This is appropriate with cathodic $\left(i_{c}\right)$ and anodik $\left(i_{a}\right)$ current peak as shown in Table 2. Evolution rates of hydrogen and oxygen depend on height of current peaks that the higher current peak the faster evolution rates of hydrogen and oxygen. Evolution potentials of hydrogen-oxygen related to Olivares, at al [15].

Based on cathodic and anodic current peak data of Fe1-5-Co-Ni/s electrodes shown $\mathrm{Fe} 1-\mathrm{Co}-\mathrm{Ni} / \mathrm{s}$ electrode was most effective (32.20 times more effective for hydrogen and 10.99 times more effective for oxygen evolutions than stainless steel).

It was explained of GSA data that Fe3-Co-Ni/s and Fe5-Co-Ni/s electrodes had area specific surface relatively greater than $\mathrm{Fe} 1-\mathrm{Co}-\mathrm{Ni} / \mathrm{s}$ electrode, but did not have more effectiveness. The increasing amount of $\mathrm{Fe}$ composition had shown character of Ni electrocatalyst decreased or deactivated. The mechanism of the hydrogen evolution in this study can be summarized
$\mathrm{M}(s)+\mathrm{H}^{+}(q)+\mathrm{e} \rightarrow \mathrm{MH}(a d s)$
(1)
$\mathrm{H}(a d s)+\mathrm{H}(a d s) \rightarrow \mathrm{H}_{2}(g)$

which $\mathrm{M}$ is metal, and the most effective is Ni. The more amount of $\mathrm{H}(a d s)$ on surface electrode the more $\mathrm{H}_{2}(g)$ evoluted. The reactions appropriate with Barber, et al, Conway and Tilak, Bianchi, et al [16-18]. 


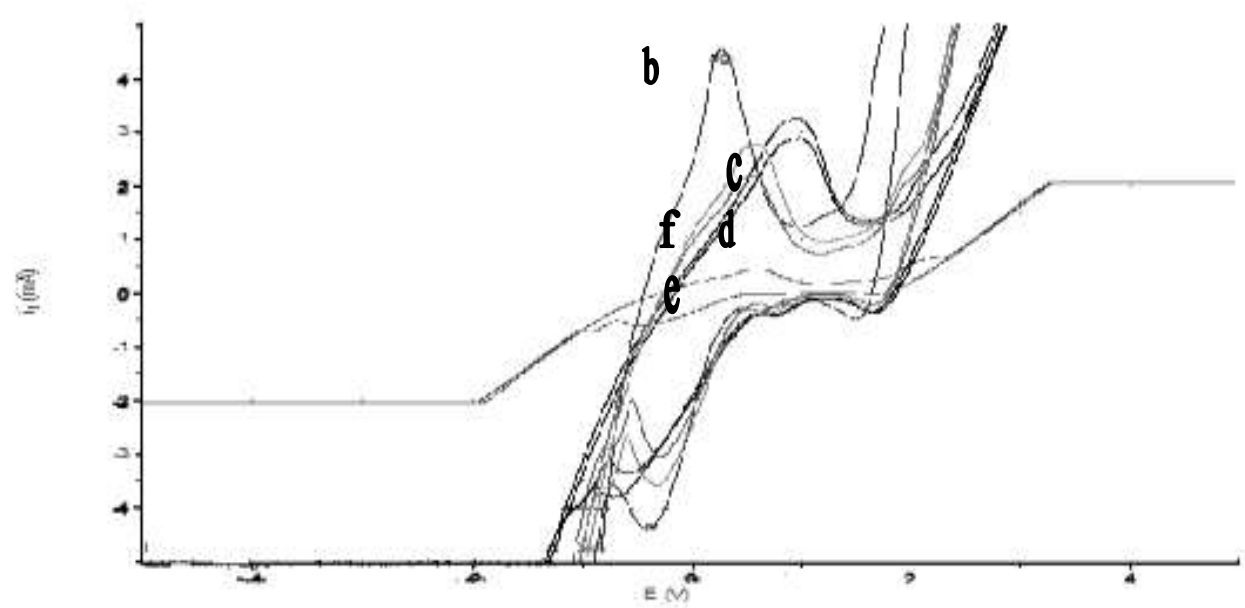

Figure 2. Cyclic voltamograms of (a) stainless steel and (b-f) Fe1-5-Co-Ni/s electrodes on water electrolysis by adding $5 \mathrm{~g}$ of $\mathrm{NaHCO}_{3}$ in one liter water

\section{Conclusion}

Based on result and discuss, it can be summarizucu that:

1. Coating of ternary metal of $\mathrm{Fe}, \mathrm{Co}$ and $\mathrm{Ni}$ onto stainless steel substrat have been able to enhanced the rate of the reaction of hydrogen evolution.

2. The increasing amount of $\mathrm{Fe}$ composition had shown character of $\mathrm{Ni}$ electrocatalyst decreased or deactivated due to power passivations.

3. Fe1-Co-Ni/s electrocatalyst electrode $(\mathrm{Fe}=57.09 \%, \mathrm{Co}=0.22 \%$ and $\mathrm{Ni}=0.74 \%)$ is the most effective to catalyze water electrolisys in base solution.

4. Catalytic effectivity of $\mathrm{Fe} 1-\mathrm{Co}-\mathrm{Ni} / \mathrm{s}$ is 32.2 times greater for producing hydrogen gas and 11 times for producing oxygen compared with stainless steel electrode.

\section{Acknowledgements}

This research was performed for the Dissertation, Doctoral Programme of Gadjah Mada University, Indonesia, funded by the Ministry of Cultural and Education of Indonesia. One of the authors, (ISYL) wishes to thank the Indonesian Ministry of Cultural and Education for award of fellowship (2007-2010).

\section{References}

[1] I.A. Raj, K.I. Vasu, J. Appl. Electrochem., 20, 1990, 32-38

[2] E. Endoh, H. Otouma, T. Morimoto, Y. Oda, Int. J. Hydrogen Energy, 12, 1987, 473

[3] Y. Choquette, H. Menard, L. Brossard, Int. J. Hydrogen Energy, 14, 1989, 637

[4] I.A. Raj, J. Appl. Electrochem., 22, 1992, 471-477

[5] Q. Han, K. Liu, J. Chen, X. Wei, Int. J. Hydrogen Energy, 28, 2004, 1207-1212.

[6] H. He, H. Liu, F. Liu, K. Zhou, Mater. Lett., 59, 2005, 3968-3972

[7] L.S. Sanches, S.H. Domingues, C.E.B. L.H. Marino, Mascaro, Electrochem. Commun. 6, 2004, 543-548

[8] J. Panek, A. Serek, A. Budniok, E. R_winski, E. Lagiewka, Int. J. Hydrogen Energy, 28 ,2003, 169

[9] J. Kubisztal, A. Budniok, Appl. Surface Sci. $252,2006,8605-8610$

[10] J. Kubisztal, A. Budniok, A. Lasia, Int. J. Hydrogen Energy, 32, 2007, 1211-1218

[11] F.C. Crnkovic, S.A.S. Machado, Avaca, L. A., Int. J. Hydrogen Energy, 29, 2004, 249-254

[12] M. Jayalakshmi, Woo-Young Kim, Kwang-Deog Jung, Oh-Shim Joo, Int. J. Electrochem. Sci., 3, 2008,908 - 917

[13] E. Navarro-Flores, S. Omanovic, J. Mol. Catal. A: Chem., 242, 2005 182-194.

[14] M. Jayalakshmi, I. Puspitasari, Kwang-Deog Jung, Oh-Shim Joo, Int. J. Electrochem. Sci., 3, 2008787 - 796

[15] J.M. Olivares-Ramirez, M.L. Campos-Cornelio, J. Uribe Godinez, E.Borja-Arco, R.H. Castellanos, Int. J. Hydrogen Energy, 32, 2007, 3170-3173

[16] J. Barber, S. Morin, B.E. Conway, J. Electroanal. Chem., 446, 1998, 125

[17] B.E. Conway, B.V. Tilak, Adv. Catalysis, 38, 1992, 1.

[18] I. Bianchi, E. Guerrini, S. Trasatti,Chemical Physics, 319, 2005, 192-199 